J. Dairy Sci. 92:3027-3039

doi:10.3168/jds.2008-1773

(c) American Dairy Science Association, 2009.

\title{
Pathogen detection in milk samples by ligation detection reaction-mediated universal array method
}

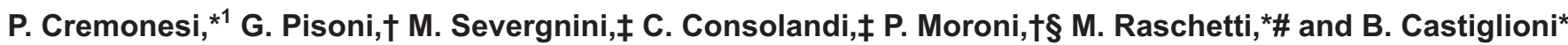 \\ *Institute of Agricultural Biology and Biotechnology-Italian National Research Council, Via Bassini 15, 20133 Milan, Italy \\ †Department of Veterinary Pathology, Hygiene and Public Health, University of Milan, Via Celoria 10, 20133 Milan, Italy \\ łInstitute of Biomedical Technologies-Italian National Research Council, Via Fratelli Cervi 93, 20090 Segrate, Milan, Italy \\ §Centro Interdipartimentale di Studi sulla Ghiandola Mammaria (CISMA), Via Celoria 10, 20133 Milan, Italy \\ \#Department of Veterinary Science and Technology for Food Safety, University of Milan, Via Trentacoste 2, 20134 Milan, Italy
}

\begin{abstract}
This paper describes a new DNA chip, based on the use of a ligation detection reaction coupled to a universal array, developed to detect and analyze, directly from milk samples, microbial pathogens known to cause bovine, ovine, and caprine mastitis or to be responsible for foodborne intoxication or infection, or both. Probes were designed for the identification of 15 different bacterial groups: Staphylococcus aureus, Streptococcus agalactiae, nonaureus staphylococci, Streptococcus bovis, Streptococcus equi, Streptococcus canis, Streptococcus dysgalactiae, Streptococcus parauberis, Streptococcus uberis, Streptococcus pyogenes, Mycoplasma spp., Salmonella spp., Bacillus spp., Campylobacter spp., and Escherichia coli and related species. These groups were identified based on the 16S rRNA gene. For microarray validation, 22 strains from the American Type Culture Collection or other culture collections and 50 milk samples were tested. The results demonstrated high specificity, with sensitivity as low as 6 fmol. Moreover, the ligation detection reaction-universal array assay allowed for the identification of Mycoplasma spp. in a few hours, avoiding the long incubation times of traditional microbiological identification methods. The universal array described here is a versatile tool able to identify milk pathogens efficiently and rapidly.
\end{abstract}

Key words: foodborne pathogen, ligase detection reaction, deoxyribonucleic acid array, mastitis

\section{INTRODUCTION}

Mastitis, the inflammation of the mammary gland, is a multifactorial disease usually caused by a microbial infection, which causes primarily lower milk yield, reduced milk quality, and greater production costs. Many different contagious and environmental bacteria cause

Received October 2, 2008.

Accepted March 24, 2009.

${ }^{1}$ Corresponding author: paola.cremonesi@unimi.it mastitis, including Staphylococcus aureus, Streptococcus agalactiae, several Mycoplasma spp., Escherichia coli, Streptococcus dysgalactiae, Streptococcus uberis, and $\mathrm{Ba}$ cillus spp. (Oviedo-Boyso et al., 2007). Staphylococcus aureus is one of the most significant pathogens causing IMI and mastitis in dairy ruminants in many countries, such as Slovenia, the Netherlands, and Italy (Pengov, 2006). Streptococcus uberis, isolated from mammary glands, is responsible for clinical and subclinical mastitis during both the nonlactating and lactation periods (Jayarao et al., 1999). There are many other streptococci that can generate unusual cases of mastitis, such as Streptococcus bovis, Streptococcus canis, Streptococcus pyogenes, and Streptococcus equi ssp. zooepidemicus (Watts et al., 1984; Devriese et al., 1999; Hassan et al., 2005; Blood et al., 2006; Pisoni et al., 2009). In addition, CNS, a group of staphylococcal species that are part of normal skin flora and that have been traditionally considered to be minor mastitis-related pathogens, have become the predominant pathogens causing subclinical or mild clinical mastitis in many countries (HonkanenBuzalski et al., 1994; Pitkala et al., 2004). Finally, mastitis caused by Mycoplasma (especially Mycoplasma bovis in cattle) appears to be an emerging problem (Fox et al., 2005), because no effective treatment exists for this form of mastitis, and infected cows are considered positive for life.

At the same time, raw milk and dairy products made from nonpasteurized milk have been responsible for Staph. aureus, Campylobacter, Salmonella, Bacillus, and E. coli outbreaks and could also represent a hazard for consumers (Allos, 2001; Granum, 2001; Little et al., 2008). Escherichia coli and related species (Bottero et al., 2004), Salmonella (Jayarao et al., 2006), and Bacillus cereus (Wong et al., 1988) are well-known organisms that are potentially very dangerous for human health.

Pathogen identification has traditionally been based on microbiological techniques that are time-consuming, generally requiring at least 2 to 3 working days and, in some conditions, not having a satisfying diagnostic sensitivity. For example, isolation and microbiologi- 
cal identification of $M$. bovis require different specific growth media and long incubation times (Gonzàlez and Wilson, 2003).

From a clinical point of view, the limited diagnostic sensitivity of bacteriology is not sufficient to exclude any infection because a negative bacteriological result does not necessarily mean that the corresponding quarter is actually free of a pathogen infection. Consequently, a considerable number of infected cows remain undetected, and the control and eradication of pathogen mastitis in herds are therefore difficult. The development of PCR-based methods has provided a promising option for the rapid detection of bacteria, even in cases of difficult-to-detect subclinical mastitis. In recent years, DNA microarray technology has played an increasingly important role in bacterial studies, including detection and quantitative analyses (Castiglioni et al., 2004; Pingle et al., 2007). The DNA microarrays were developed for simultaneous analysis of Staph. aureus enterotoxin genes, Listeria spp., Campylobacter spp., and Clostridium perfringens toxin genes (Sergeev et al., 2004). More recently, Wang et al. (2007) described a 16S rRNA oligonucleotide microarray to identify 22 common pathogenic species, whereas Kim et al. (2008) developed a microarray for the detection of the main foodborne pathogens.

In this study, a microarray platform, based on the discriminative properties of the DNA ligation detection reaction (LDR), associated with a universal tag-array (UA), was developed and used to identify pathogens such as Staph. aureus, Strep. agalactiae, nonaureus staphylococci (NAS), Strep. bovis, Strep. equi, Strep. canis, Strep. dysgalactiae, Streptococcus parauberis, Strep. uberis, Strep. pyogenes, Mycoplasma spp., Salmonella spp., Bacillus spp., Campylobacter spp., and E. coli and related species.

\section{MATERIALS AND METHODS}

\section{DNA Samples}

The specificity and sensitivity of the LDR probe pairs were tested with DNA extracted from 22 American Type Culture Collection (ATCC) reference strains (LGC Promochem, Middlesex, UK) or isolates listed in Table 1, using the DNA extraction protocol described in Cremonesi et al. (2006). The LDR probe pairs were further evaluated with DNA extracted from a total of 50 milk samples (42 bovine, 2 ovine and 3 caprine mastitic samples plus 3 bovine milk samples from healthy cows), also collected for bacteriological examinations. For the specificity and microarray validation experiments, $50 \mathrm{fmol}$ of the purified $16 \mathrm{~S}$ rRNA PCR product were used. For the sensitivity assays, 50, 25, 12.5, and 6 fmol of the PCR product was used.

\section{Bacteriological Procedures}

Bacteriological culturing of quarter and udder half milk samples was performed according to standards of the National Mastitis Council (1999). Briefly, $10 \mu \mathrm{L}$ of each milk sample was spread on blood agar plates (5\% defibrinated sheep blood, Microbiol Diagnostici, Cagliari, Italy). The plates were incubated aerobically at $37^{\circ} \mathrm{C}$ and examined after 24 and $48 \mathrm{~h}$. The colonies were provisionally identified on the basis of gram stain, morphology, and hemolysis patterns and the numbers of each colony type were recorded. The representative colonies were then subcultured on blood agar plates and incubated aerobically at $37^{\circ} \mathrm{C}$ for $24 \mathrm{~h}$ to obtain pure cultures. Production of catalase and coagulase was tested for gram-positive cocci. Specific identifications of staphylococci and streptococci were made using commercial micromethods (API Staph ID32 system and API 20 Strep, respectively, bioMérieux, Rome, Italy). Gram-negative isolates were identified by use of colony morphology, gram-staining characteristics, oxidase, and biochemical reactions on MacConkey's agar and API 20E (bioMérieux). Ten microliters of milk was also plated onto a Hayflick agar plate (Brown et al., 1990) containing $15 \%$ horse serum; agar plates were incubated at $35^{\circ} \mathrm{C}$ with $5 \% \mathrm{CO}_{2}$ and examined using a $40 \times$ stereomicroscope for Mycoplasma growth every 48 $\mathrm{h}$ until such time as colonies were obtained, or for $10 \mathrm{~d}$ if no colonies were identified.

\section{PCR Amplifications from DNA Samples}

The 16S rRNA gene was amplified with universal primers 16S27F (5'-AGA GTT TGA TCC TGG CTC AG-3') and R1492 (5'-TAC GGY TAC CTT GTT ACG ACT T-3'; Edwards et al., 1989). The PCR amplifications were performed with a GeneAmp PCR system 9700 thermal cycler (Applied Biosystems, Foster City, $\mathrm{CA})$. The reaction mixtures included $0.85 \mu \mathrm{L}$ of each primer $(15 \mu M), 10 \mu \mathrm{L}$ of $2 \times$ PyroStart Fast PCR Master Mix (Fermentas, M-Medical SRL, Milan, Italy), and 10 to $15 \mathrm{ng}$ of genomic DNA in a final volume of $20 \mu \mathrm{L}$. Before amplification, DNA was denatured for $1 \mathrm{~min}$ at $95^{\circ} \mathrm{C}$. Amplification consisted of 30 cycles at $94^{\circ} \mathrm{C}$ for $1 \mathrm{~s}, 61^{\circ} \mathrm{C}$ for $5 \mathrm{~s}$, and $72^{\circ} \mathrm{C}$ for $38 \mathrm{~s}$. After the cycles, an extension step $\left(10 \mathrm{~s}\right.$ at $\left.72^{\circ} \mathrm{C}\right)$ was performed. The PCR products were purified by using a Wizard SV gel and PCR Clean-Up System purification kit (Promega Italia, Milan, Italy), according to the instructions of the manufacturer, eluted in $20 \mu \mathrm{L}$ of molecular grade 
Table 1. Origin, signal-to-noise-ratio (SNR), and $t$-test unadjusted $P$-values for ligation detection reaction probe pair specificity tests ${ }^{1}$

\begin{tabular}{|c|c|c|c|c|c|c|}
\hline Organism & Species & $\begin{array}{l}\text { Bacterial } \\
\text { collection }\end{array}$ & Probe name & $\begin{array}{l}\text { SNR-specific } \\
\text { probe }\end{array}$ & $\begin{array}{c}\text { Average SNR } \\
\text { of other probes } \\
(\mathrm{n}=14)\end{array}$ & $\begin{array}{l}P \text {-value for the } \\
\text { specific probe }\end{array}$ \\
\hline Bacillus & Bacillus cereus & ATCC 14579 & Bacillus spp. & 45.30 & 0.43 & $3.90 \mathrm{E}-06$ \\
\hline \multirow[t]{6}{*}{ Campylobacter } & \multirow[t]{2}{*}{ Campylobacter coli } & \multirow[t]{2}{*}{ ATCC 1061} & Campylobacter spp._179 & 6.49 & 0.33 & $1.68 \mathrm{E}-07$ \\
\hline & & & Campylobacter spp._234 & 3.43 & 0.33 & $1.70 \mathrm{E}-04$ \\
\hline & Campylobacter lari & ATCC BAA1060 & Campylobacter spp._179 & 42.62 & 1.22 & $6.75 \mathrm{E}-06$ \\
\hline & \multirow{3}{*}{ Campylobacter jejuni } & \multirow{3}{*}{ ATCC 33560} & & 20.12 & 0.71 & $2.58 \mathrm{E}-06$ \\
\hline & & & Campylobacter spp._234 & 21.26 & 1.11 & 8.70E-04 \\
\hline & & & & 20.12 & 0.71 & $9.91 \mathrm{E}-05$ \\
\hline \multirow[t]{2}{*}{ Escherichia coli } & \multirow[t]{2}{*}{ E. coli $\mathrm{O} 157$} & \multirow[t]{2}{*}{ ATCC 700927} & \multirow[t]{2}{*}{ E. coli_et_rel } & 9.56 & 0.56 & $2.57 \mathrm{E}-07$ \\
\hline & & & & 22.68 & 0.73 & $5.62 \mathrm{E}-09$ \\
\hline \multirow{3}{*}{ Mycoplasma } & \multirow[t]{2}{*}{ M. agalactiae } & \multirow{2}{*}{ DIPAEE $^{2}$} & \multirow[t]{3}{*}{ Mycoplasma spp. } & 42.28 & 0.83 & $2.11 \mathrm{E}-06$ \\
\hline & & & & 42.76 & 0.80 & $7.29 \mathrm{E}-04$ \\
\hline & M. mycoides & DIPAEE & & 7.38 & 0.20 & $4.42 \mathrm{E}-05$ \\
\hline \multirow{2}{*}{ Salmonella } & \multirow{2}{*}{ Salmonella enteritidis } & ATCC 13076 & Salmonella spp. & 10.98 & 0.51 & $2.20 \mathrm{E}-08$ \\
\hline & & & & 11.74 & 0.51 & $7.95 \mathrm{E}-11$ \\
\hline Staphylococcus & Staph. aureus & ATCC 19095 & Staph. aureus & 5.76 & 0.23 & $1.51 \mathrm{E}-04$ \\
\hline & & & & 10.05 & 0.42 & $4.90 \mathrm{E}-10$ \\
\hline & Staph. epidermidis & ISPA-CNR $^{3}$ & $\mathrm{NAS}^{4}$ & 4.31 & 0.20 & $7.51 \mathrm{E}-03$ \\
\hline & & & & 46.76 & 0.83 & $1.11 \mathrm{E}-06$ \\
\hline & Staph. sciuri & DIPAV $^{5}$ & & 9.29 & 0.91 & $7.47 \mathrm{E}-04$ \\
\hline & & & & 10.68 & 0.96 & $8.90 \mathrm{E}-05$ \\
\hline & Staph. hemolyticus & DIPAV & & 27.89 & 0.83 & $8.11 \mathrm{E}-08$ \\
\hline & & & & 29.78 & 1.03 & $7.64 \mathrm{E}-05$ \\
\hline Streptococcus & Strep. agalactiae & ATCC BAA611 & Str. agalactiae & 7.04 & 0.12 & $1.39 \mathrm{E}-07$ \\
\hline & & & & 35.32 & 0.57 & $1.20 \mathrm{E}-07$ \\
\hline & Strep. uberis & ATCC 9927 & Str. uberis & 14.46 & 0.42 & $1.24 \mathrm{E}-09$ \\
\hline & Strep. equi & DIPAV & Str. equi & $\begin{array}{l}73.25 \\
13.09\end{array}$ & $\begin{array}{l}0.58 \\
0.38\end{array}$ & $\begin{array}{l}9.95 \mathrm{E}-08 \\
4.22 \mathrm{E}-06\end{array}$ \\
\hline & & & & 48.30 & 1.11 & $1.94 \mathrm{E}-07$ \\
\hline & Strep. pyogenes & ATCC 12344 & Str. pyogenes & 93.69 & 1.39 & $1.79 \mathrm{E}-07$ \\
\hline & & & & 118.71 & 1.55 & $9.71 \mathrm{E}-14$ \\
\hline
\end{tabular}

${ }^{1}$ For each sample, the bacterial collection reference, the SNR of the specific probe, and the SNR of all the remaining (nonspecific) probes are reported. $P$-values are calculated as the results of a one-sided $t$-test comparison between the intensity of fluorescence of each probe and those of the Blank spots.

${ }^{2}$ Department of Livestock Production, Epidemiology and Ecology, Faculty of Veterinary Medicine, University of Turin, Turin, Italy.

${ }^{3}$ Institute of Sciences of Food Production-Italian National Research Council, Milan, Italy.

${ }^{4} \mathrm{NAS}=$ nonaureus staphylococci.

${ }^{5}$ Department of Animal Pathology, Hygiene and Veterinary Public Health, University of Milan, Milan, Italy.

water, and quantified by capillary electrophoresis on an Agilent BioAnalyzer 2100 (Agilent Technologies, Palo Alto, CA).

\section{LDR Probe Design for the 16S rRNA Gene}

We designed specific LDR probe pairs for the $16 \mathrm{~S}$ rRNA gene sequences of 15 different bacterial groups:
Staph. aureus, Strep. agalactiae, NAS, Strep. bovis, Strep. equi, Strep. canis, Strep. dysgalactiae, Strep. parauberis, Strep. uberis, Strep. pyogenes, Mycoplasma spp., Salmonella spp., Bacillus spp., Campylobacter spp., and E. coli and related species. Probe pairs for Strep. equi and Strep. dysgalactiae were designed to identify any of the 2 subspecies of each. For each of these groups, 16S 


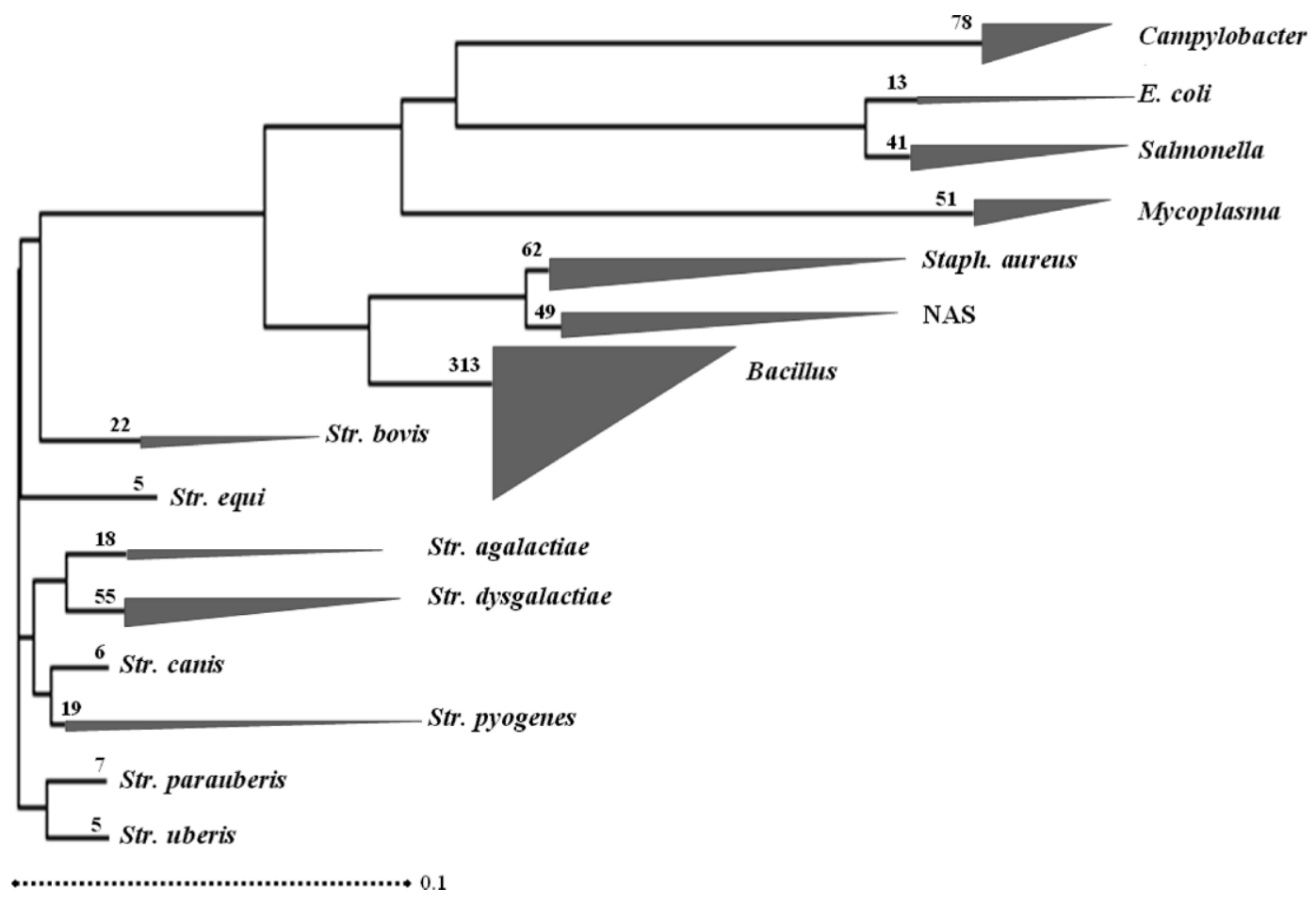

Figure 1. Schematic of the grouping and clustering of the $16 \mathrm{~S}$ rRNA gene sequences. For each node, the number of sequences used from the Ribosomal Database Project II database (length $>1,200$ bp and "good" quality) is reported. The dimension of the triangles is proportional to the number of sequences that were clustered together. The phylogenetic tree was built on the 15 consensus sequences by using the neighbor-joining algorithm and Phylip tree type. The scale represents the number of differences between sequences (e.g., 0.1 means $10 \%$ differences between 2 sequences). NAS = nonaureus staphylococci.

rRNA sequences longer than $1,200 \mathrm{bp}$ and flagged as being of "good quality," chosen among those available in the Ribosomal Database Project (RDP) II, release 9.51 (http://rdp.cme.msu.edu/html/), were selected. A total of 744 sequences were used for the consensus determination and probe design (Figure 1). Sequences belonging to the same subgroups were then aligned together by ClustalW (Chenna et al., 2003) and imported into the Oligonucleotide Retrieving for Molecular Applications (ORMA) tool (M. Severgnini, P. Cremonesi, C. Consolandi, B. Castiglioni; and G. Caredda and G. De Bellis of the Institute of Biomedical TechnologiesItalian National Research Council, Segrate; unpublished data). This software is based on a set of scripts under Matlab (Mathworks, Natick, MA) to retrieve positions discriminating each sequence from the others, design optimal probes on the found positions, and quality filter the candidates, driving the user to the determination of thermodynamically optimized oligonucleotides. The consensus sequences for each subgroup were obtained according to the algorithm by Ludwig et al. (2004), setting a cutoff threshold of $40 \%$ and substituting, where necessary, multiple bases above the given threshold with the corresponding International Union of Pure and Applied Chemistry ambiguity code. The sequences were then realigned with ClustalW and used in the ORMA tool for probe design.

We required the melting temperature to be within the 66 to $68^{\circ} \mathrm{C}$ range, with a length of between 25 and 50 bases; a maximum of 5 degenerated bases per oligonucleotide were allowed. Three rounds of design were performed: 1) Salmonella spp. was aligned against the E. coli sequence only; 2) Strep. canis and Strep. pyogenes were aligned against Streptococcus group sequences only (i.e., all Streptococcus species included in the LDR assay); and 3) all other probe pairs were selected considering the alignment of all the species. One probe per species or genus was designed, except for Campylobacter spp., for which 2 different positions were tested, to compare and verify their specificity and performances.

The specificity of the probe pairs was checked with both the Probe Match tool in RDP II database and BLAST (Basic Local Alignment Search Tool) analysis (Altschul et al., 1997). Each common probe was synthesized to have a complementary ZipCode (cZipCode) affixed to the $3^{\prime}$ end, and a phosphate modification to the $5^{\prime}$ end. A Cy3 label was attached to the $5^{\prime}$ end of the discriminating probes. In LDR, if both probes are annealed to the target sequence, the fluorescent dye 
and the cZipCode are linked into the same molecule. In hybridization, a cZipCode pairs with its corresponding ZipCode, addressing the fluorescent signal to a specific spot on a glass slide. All the oligonucleotides (Table 2) were synthesized by Thermo Electron GmbH (Ulm, Germany). When a probe sequence contained an ambiguity code, this base was replaced with inosine during oligonucleotide synthesis.

\section{UA Preparation}

Phenylen-diisothiocyanate-activated chitosan glass slides were used as surfaces for the preparation of microarrays (Consolandi et al., 2006). Microarrays were prepared as described in Castiglioni et al. (2004), using a MicroGrid II Compact (Biorobotics, Cambridge, UK) contact pin spotter equipped with Silicon Microarray pins (Parallel Synthesis Technologies, Santa Clara, CA). For the present study, 17 ZipCodes, randomly selected from the 49 of the entire UA layout described in Chen et al. (2000), were assigned for the recognition of bacterial group based on the 16S rRNA gene. ZipCode 66 (hybridization control) and ZipCode 63 (ligation control) were used to locate the submatrixes during the scanning and to verify the success of the ligation procedure, respectively.

\section{LDR, UA Hybridization, and Signal Detection}

All the group-specific probe pairs were added into an oligo-mix, at a concentration of $1 \mu M$ each. The oligo-mix also contained a discriminating and a common probe specific for the synthetic oligonucleotide used as the LDR control (5'-AGC CGC GAA CAC CAC GAT CGA CCG GCG CGC GCA GCT GCA GCT TGC TCA TG-3'). The LDR was carried out in a final volume of $20 \mu \mathrm{L}$ containing $1 \mu \mathrm{L}$ of $10 \times P f u$ DNA Ligase Buffer (Stratagene, La Jolla, CA), $1 \mu \mathrm{L}$ of oligo-mix, $1 \mu \mathrm{L}$ of Pfu DNA ligase (Stratagene), and $0.1 \mu \mathrm{L}$ of the synthetic oligonucleotide. The reaction mixture was preheated for $5 \mathrm{~min}$ at $94^{\circ} \mathrm{C}$ and was then cycled for 30 rounds at $94^{\circ} \mathrm{C}$ for $30 \mathrm{~s}$ and at $65^{\circ} \mathrm{C}$ for 4 min. Hybridization, slide washing, and data acquisition were performed following the procedures described in Castiglioni et al. (2004). Briefly, the hybridization mixture had a total volume of $65 \mu \mathrm{L}$ and contained 20 $\mu \mathrm{L}$ of LDR mixture, $5 \times$ saline sodium citrate $(\mathbf{S S C}$, Sigma-Aldrich, Milan, Italy), $0.1 \mu M$ Cy3-labeled cZipCode 66 (complementary to ZipCode 66), and $0.1 \mathrm{mg} /$ $\mathrm{mL}$ of salmon sperm DNA. After heating at $94^{\circ} \mathrm{C}$ for 2 min and chilling on ice, the hybridization mixture was applied to the slide, on which the 8 arrays were separated by Press-To-Seal silicone isolators $(1.0 \times 9 \mathrm{~mm}$; Schleicher and Schuell BioScience, Dassel, Germany).
By using 8 subarrays per slide, associated with a multichamber hybridization system, 8 samples were run in parallel on the same slide. Hybridization was carried out in a dark chamber at $65^{\circ} \mathrm{C}$ for $1 \mathrm{~h} 30 \mathrm{~min}$ in a temperature-controlled water bath. After hybridization, the slide was washed at $65^{\circ} \mathrm{C}$ for $15 \mathrm{~min}$ in prewarmed $1 \times$ SSC. Finally, the slide was dried by spinning at 80 $\times g$ for $3 \mathrm{~min}$. The fluorescent signals were acquired at a $5-\mu \mathrm{m}$ resolution by using a ScanArray Lite laserscanning system (PerkinElmer Life and Analytical Sciences, Boston, MA) with a green laser for Cy3 dye $\left(\lambda_{\text {ex }}\right.$, $\left.543 \mathrm{~nm} ; \lambda_{\mathrm{em}}, 570 \mathrm{~nm}\right)$. The power of both the laser and the photomultiplier tube was set between 70 and $95 \%$, depending on the signal intensities, avoiding saturation in any case.

\section{Data Analysis}

Intensities of fluorescence (IF) were quantified by ScanArray Express 3.1 software (PerkinElmer), using the "adaptive circle" option, allowing diameters between 60 and $300 \mu \mathrm{m}$. No normalization was performed on IF because the experiments were analyzed independently of one another. All statistical tests and data analyses were performed in Matlab. To assess whether a probe was significantly above the background, a one-sided Student $t$-test $(\alpha=0.01)$ was performed, using the IF of "Blank" spots (i.e., with no oligonucleotide spotted, $\mathrm{n}=6$ ), plus 2 times their standard deviations, as a conservative estimation of the null distribution. For each ZipCode, we considered the population of the IF of all the replicates $(n=4)$ and tested it for being significantly above the null distribution $\left(\mathrm{H}_{0}: \mu_{\text {test }}=\mu_{\text {null }}\right.$; $\left.\mathrm{H}_{1}: \mu_{\text {test }}>\mu_{\text {null }}\right)$. The signal-to-noise ratio (SNR) was calculated as the ratio between the average IF of each probe and the average Blank spots for IF; coefficient of variation percentages represent the percentage ratio of the standard deviation of IF on their average values.

\section{RESULTS}

\section{Group-Specific SNP Identification}

The ORMA probe design tool (M. Severgnini, P. Cremonesi, C. Consolandi, B. Castiglioni; and G. Caredda and G. De Bellis of the Institute of Biomedical Technologies-Italian National Research Council, Segrate; unpublished data) was used in our study for SNP identification and LDR probe design on 16S rRNA, allowing the precise determination and detection of the main pathogens infecting cattle, sheep, and goats or those responsible for foodborne intoxication or infection, or both. The BLAST analysis and the "Probe Match" tool in the RDP II database were used to confirm in silico 
Table 2. List of group-specific probes and corresponding ZipCodes

\begin{tabular}{|c|c|c|c|c|}
\hline Probe pair name & Discriminating probe $^{1}\left(5^{\prime}-3^{\prime}\right)$ & Common probe ${ }^{2}\left(5^{\prime}-3^{\prime}\right)$ & $\begin{array}{l}\text { SNP } \\
\text { position }\end{array}$ & ZipCode $^{3}$ \\
\hline Staph. aureus & $\begin{array}{l}\text { TAA TAC CGG ATA ATA TTT TGA ACC GCA } \\
\text { TGG TTC AAA AGT GAA AGA CGG TC }\end{array}$ & $\begin{array}{l}\text { TTG CTG TCA CTT ATA GAT GGA TCC GCG } \\
\text { CTG CAT TAG CTA GTT GGT AA }\end{array}$ & 222 & 2 \\
\hline Strep. canis & $\begin{array}{l}\text { CGT AAA GCT CTG TTG TTA GAG AAG } \\
\text { AAC GGT AAT GGG AGT GGA AAA C }\end{array}$ & $\begin{array}{l}\text { CCA TTA TGT GAC GGT AAC TAA CCA } \\
\text { GAA AGG GAC GGC TAA CTA C }\end{array}$ & 474 & 3 \\
\hline Strep. dysgalactiae & $\begin{array}{l}\text { GGT CTA GAG ATA GGC TTT } \\
\text { CCC TTC GGG GCA GG }\end{array}$ & AGT GAC AGG TGG TGC ATG GTT GTC GTC AGC TCG & 1061 & 4 \\
\hline Salmonella spp. & $\begin{array}{l}\text { CCA TCA GAT GTG CCC AGA TGG } \\
\text { GAT TAG CTT GTT GGT GA }\end{array}$ & GGT AAC GGC TCA CCA AGG CGA CGA TCC CTA G & 251 & 5 \\
\hline Campylobacter spp_179 & $\begin{array}{l}\text { CCC TAC ACA AGA GGA CAA CAG } \\
\text { TTG GAA ACG ACT GCT AAT ACT }\end{array}$ & $\begin{array}{l}\text { CTA TAC TCC TGC TTA ACA CAA GTT GAG } \\
\text { TAG GGA AAG TTT TTC GGT GTA }\end{array}$ & 179 & 8 \\
\hline Campylobacter spp_234 & $\begin{array}{l}\text { CTC TAT ACT CCT GCT TAA CAC AAG } \\
\text { TTG AGT AGG GAA AGT TTT TCG } \mathbf{G}\end{array}$ & $\begin{array}{l}\text { TGT AGG ATG AGA CTA TAT AGT ATC AGC } \\
\text { TAG TTG GTI AGG TAA TGG C }\end{array}$ & 234 & 9 \\
\hline Bacillus spp. & $\begin{array}{l}\text { CTA AGT GTT AGA GGG TTT CCG } \\
\text { CCC TTT AGT GCT GAA GT }\end{array}$ & TAA CGC ATT AAG CAC TCC GCC TGG GGA GTA CG & 880 & 10 \\
\hline Strep. equi & $\begin{array}{l}\text { CTA ATA CCG CAT AAA AGT GGT TGA CCC } \\
\text { ATG TTA ACI ATT TAA AAG GAG CAA CA }\end{array}$ & GCT CCA CTA TGA GAT GGA CCT GCG TTG TAT TAG CTA GTT & 224 & 12 \\
\hline Strep. agalactiae & $\begin{array}{l}\text { CGT GCC TAA TAC ATG CAA GTA GAA } \\
\text { CGC TGA IGT TTG GTG TTT A }\end{array}$ & CAC TAG ACT GAT GAG TTG CGA ACG GGT GAG TAA CG & 87 & 15 \\
\hline Strep. bovis & $\begin{array}{l}\text { GCG TGC CTA ATA CAT GCA AGT AGA } \\
\text { ACG CTG AAG ACT TTA GCT TGC TAA }\end{array}$ & $\begin{array}{l}\text { AGT TGG AAG AGT TGC GAA CGG GTG } \\
\text { AGT AAC GCG TAG GTA A }\end{array}$ & 91 & 16 \\
\hline Strep. parauberis & $\begin{array}{l}\text { GCC GTG GCT CAA CCA TGG TTC } \\
\text { GCT TTG GAA ACT GGA T }\end{array}$ & $\begin{array}{l}\text { AAC TTG AGT GCA GAA GGG GAG AGT } \\
\text { GGA ATT CCA TGT GTA GC }\end{array}$ & 663 & 18 \\
\hline Strep. uberis & $\begin{array}{l}\text { AAT ACC GCA TGA CAA TAG GGT ACA CAT } \\
\text { GTA CCC TAT TTA AAA GGG GCA AA }\end{array}$ & $\begin{array}{l}\text { TGC TTC ACT ATG AGA TGG ACC TGC GTT } \\
\text { GTA TTA GCT AGT TGG TAA GGT AA }\end{array}$ & 223 & 19 \\
\hline Mycoplasma spp. & $\begin{array}{l}\text { CGI CGC AGC TAA CGC ATT AAA } \\
\text { TGA TCC GCC TGA GT }\end{array}$ & $\begin{array}{l}\text { AGT AIG ITC GCA AGA ITI AAA CTT AAA } \\
\text { GGA ATT GAC GGG GAI CC }\end{array}$ & 906 & 20 \\
\hline $\mathrm{NAS}^{4}$ & $\begin{array}{l}\text { CCG GAG CTA ATA CCG GAT AAT ATI } \\
\text { TIG AAC CGC ATG GTT CIA T }\end{array}$ & $\begin{array}{l}\text { AGT GAA AGA IGG TTT TGC TIT CAC } \\
\text { TTA TAG ATG GAI CCG CGC }\end{array}$ & 208 & 21 \\
\hline Strep. pyogenes & $\begin{array}{l}\text { GCA GGC GGT TTT TTA AGT CTG AAG } \\
\text { TTA AAG GCA TTG GCT CAA CCA A }\end{array}$ & $\begin{array}{l}\text { TGT ACG CTT TGG AAA CTG GAG AAC } \\
\text { TTG AGT GCA GAA GGG }\end{array}$ & 530 & 22 \\
\hline E. coli_et_rel & $\begin{array}{l}\text { GGG TTG TAA AGT ACT TTC AGC GGG } \\
\text { GAG GAA GGG AGT AAA GTT AAT AC }\end{array}$ & CTT TGC TCA TTG ACG TTA CCC GCA GAA GAA GCA CCG G & 484 & 28 \\
\hline
\end{tabular}

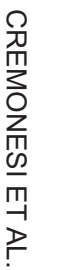

${ }^{1}$ A Cy3 label attached to the $5^{\prime}$ end; discriminating nucleotides at the 3 ' end are in bold face.

${ }^{2}$ Designed to anneal to the target sequence immediately adjacent to the discriminating probe.

${ }^{3}$ ZipCode numbers as in Chen et al. (2000).

${ }^{4} \mathrm{NAS}=$ nonaureus staphylococci. 
the specificity of the selected candidates. However, the NAS probe pair identified mostly the following species: Staphylococcus epidermidis, Staphylococcus hemolyticus, and Staphylococcus lugdunensis. Moreover, the probe pair designed for the E. coli group targeted some Shigella strains (data not shown). Because Shigella can also be found in milk samples and can potentially be harmful for human health, we decided to keep the probe pair in the assay, renaming it "E. coli_et_rel."

Where necessary, multiple rounds of design were performed to maximize the quality of the probe pairs found. In particular, the Salmonella spp. probe, whose consensus resulted in values significantly different from all the other species, was obtained by comparing its consensus with only the $E$. coli and related species consensus sequence.

\section{Specificity of the Probe Pairs}

The specificity of the probe pairs was tested separately with the $16 \mathrm{~S}$ rRNA products on a total of 22 ATCC or isolated bacterial strains (Table 1). Several examples of these results are also shown in Figure 2. No signal was detected using the Listeria monocytogenes strain ATCC 51780 as negative control (data not shown). All the LDR-UA experiments were replicated by duplicate independent LDR. Table 1 reports the SNR and the $P$-values of the $t$-tests of the assays for the probe pairs on single PCR product target. The procedure showed optimal specificity, with excellent signal-to-noise ratios. Results were in complete concordance with identification of ATCC strains and microbiological isolates: only probes associated with the expected species were present $(P$-values always $<0.005)$, whereas all remaining probes were well below any acceptable $P$-value for the $t$-test. Hybridization and ligation control probes were always significantly present (data not shown).

The SNR of the probes called as significantly over the background varied from 4.31 to 238.3 , with an average of 37.98; at the same time, SNR of the nonsignificantly over-background spots varied between 0.12 and 1.55, with an average of $0.65 \pm 0.33$. Both Campylobacter spp. probes performed nearly the same in terms of specificity, with $P$-values below $10^{-4}$. Reproducibility and homogeneity of hybridization was excellent as well, with an average coefficient of variation percentage among replicates for the present probes of $12.62 \pm$ $7.35 \%$.

\section{Sensitivity of the Probe Pairs}

To test the sensitivity of the method and the correlation between signal intensity and template concentration, the assay was evaluated by separate LDR on serial dilutions from 50 to $6 \mathrm{fmol}$ of $M$. bovis, Strep. agalactiae, Strep. pyogenes, and Staph. aureus $16 \mathrm{~S}$ rRNA-PCR products.

Figure 3 shows the SNR and the $P$-values (in logarithmic scale) of the serial dilutions of the 4 pathogen species. Considering a threshold value of 0.01 for significance of the presence of a probe, M. bovis, Strep. agalactiae, and Strep. pyogenes revealed a detection limit of $6 \mathrm{fmol}$, whereas Staph. aureus was limited to $12 \mathrm{fmol}$. As expected, SNR and $P$-values were inverselinearly correlated (Pearson correlation between -0.81 and -0.97), whereas the correlation between SNR and PCR product concentration or $P$-values and PCR product concentration are slightly lower (range 0.63 to 0.79 and 0.59 to 0.85 , respectively).

\section{Evaluation of the Probe Pairs with Milk Samples}

The performance of the LDR probe pairs was evaluated using DNA extracted from 50 milk samples, 47 of which were from mastitic animals. With bacteriological analysis of the 50 milk samples, 9 samples were found to be positive for Staph. aureus, 24 were positive for Streptococcus spp., 5 were positive for Staphylococcus spp., 9 were positive for Mycoplasma spp., and 3 were negative controls. The LDR results obtained from the analysis of these samples revealed a good correlation with those obtained from the microbiological assays (Figure 4), also showing the presence of Bacillus spp. in 2 mastitic milk samples and specifying the presence of Strep. uberis (8), Strep. agalactiae (6), Strep. dysgalactiae (3), Strep. equi (2), Strep. bovis (4), and Strep. canis (3) for the Streptococcus spp., and NAS (7) for the Staphylococcus spp. Nine samples were positive for Staph. aureus, whereas 11 were positive for Mycoplasma spp. Finally, 3 samples were negative with both bacteriological and LDR analyses.

\section{DISCUSSION}

The objective of this work was to develop an assay that could rapidly identify the main pathogens known to cause mastitis in cattle, sheep, and goats or those responsible for foodborne intoxication or infection, or both. The bacterial pathogens on the assay panel were chosen to include 1) the organisms most frequently isolated from mastitis samples, such as Staph. aureus, Strep. agalactiae, Strep. uberis, and some NAS; 2) those that have been described recently as a contagious cause of subclinical mastitis, such as Mycoplasma spp. (Fox et al., 2005); and 3) those potentially dangerous for human health, such as E. coli and related species (Bottero et al., 2004), Salmonella spp. (Jayarao et al., 2006), Staph. aureus (De Buyser et al., 2001), B. cereus (Wong et al., 


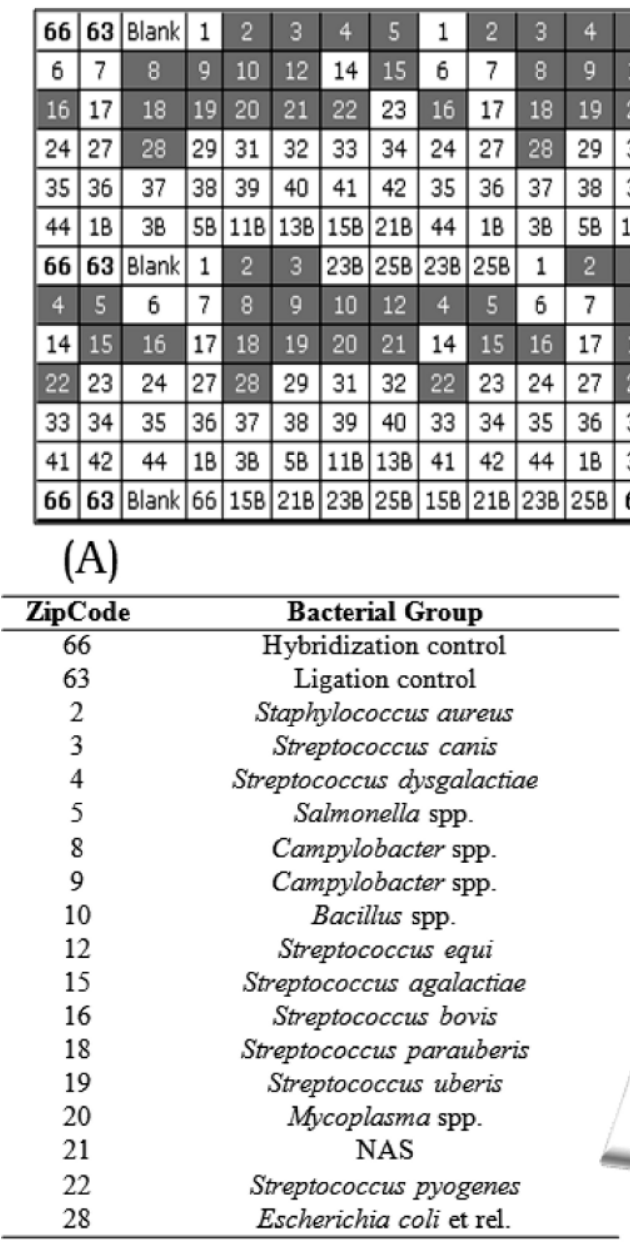

(B)
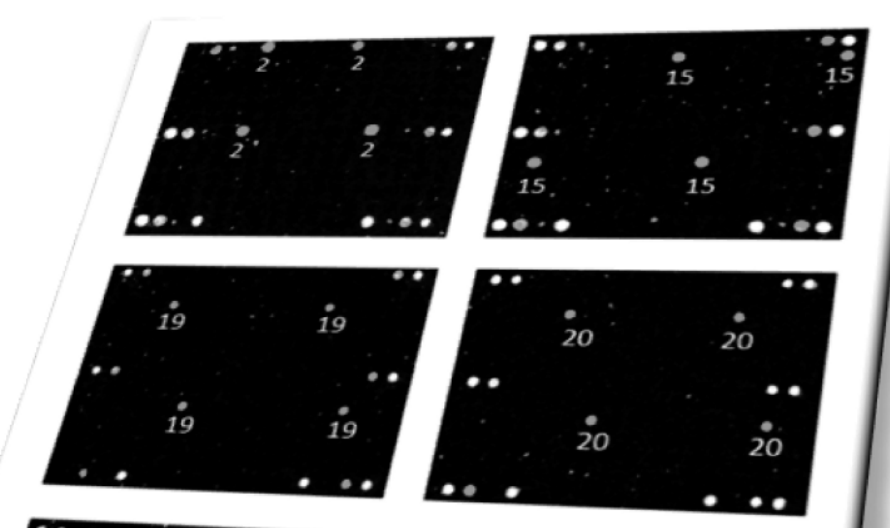

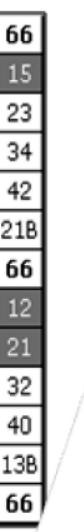

\begin{tabular}{|c|c|c|c|}
\hline 5 & Blank & 63 & 66 \\
\hline 10 & 12 & 14 & 15 \\
\hline 20 & 21 & 22 & 23 \\
\hline 31 & 32 & 33 & 34 \\
\hline 39 & 40 & 41 & 42 \\
\hline 118 & $13 B$ & $15 B$ & $21 B$ \\
\hline 3 & Blank & 63 & 66 \\
\hline 8 & 9 & 10 & 12 \\
\hline 18 & 19 & 20 & 21 \\
\hline 28 & 29 & 31 & 32 \\
\hline 37 & 38 & 39 & 40 \\
\hline $3 B$ & $5 B$ & $11 B$ & 138 \\
\hline 66 & Blank & 63 & 66 \\
\hline
\end{tabular}

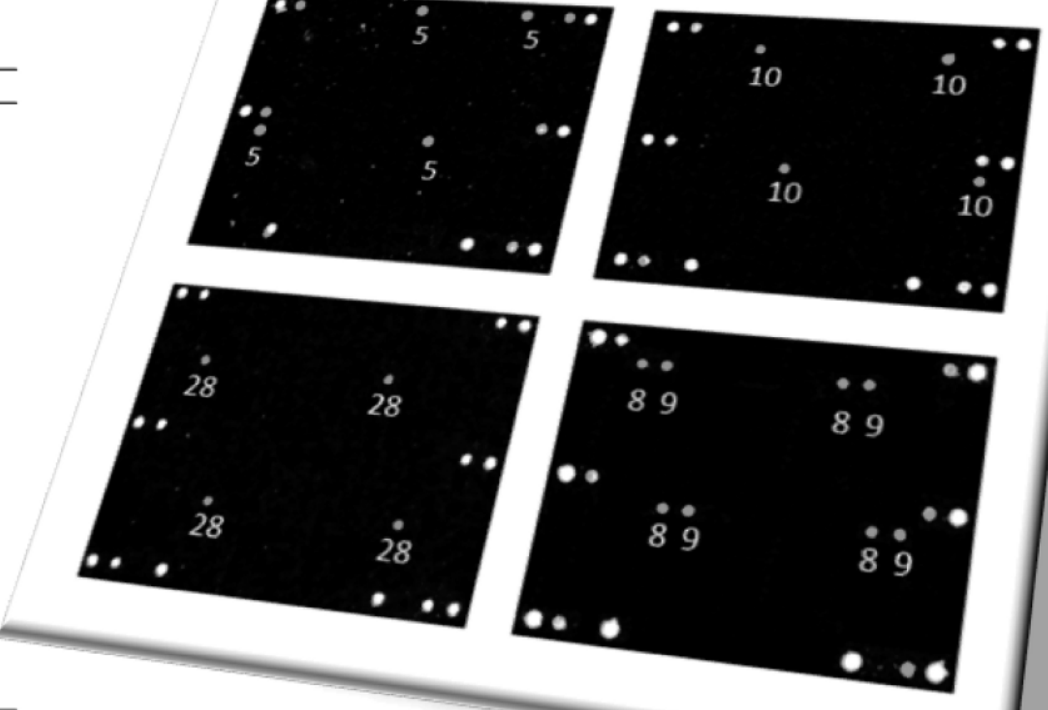

(C)

Figure 2. A) Universal array scheme. Each ZipCode is spotted in quadruplicate; oligonucleotides associated with actual probe pairs are highlighted in gray. ZipCodes 66 and 63 are the hybridization and ligation controls, respectively. Blank spots are negative controls (no oligo; only spotting buffer). B) Table specifying the bacterial groups with the corresponding ZipCode. C) Specificity results of the amplified 16S rRNA gene from Staphylococcus aureus (ATCC 19095, ZipCode 2), Salmonella enteritidis (ATCC 13076, ZipCode 5), Campylobacter coli (ATCC 1061, ZipCodes 8 and 9), Bacillus cereus (ATCC 14579. ZipCode 10). Streptococcus agalactiae (ATCC BAA611D, ZipCode 15), Streptococcus uberis (ATCC 9927, ZipCode 19), Mycoplasma bovis (ATCC 25523, ZipCode 20), and Escherichia coli O157 (ATCC 700927, ZipCode 28). Each bacterial group has 4 replicate spots. ZipCode numbers of the specific probes are reported under each replicate. Lighted spots at the corners represent the hybridization and ligation controls (spots 66 and 63), as in the universal array scheme (A). NAS = nonaureus staphylococci.

1988), and Strep. equi ssp. zooepidemicus (Bergonier et al., 1999).

In the last decade, many molecular diagnostic methods have been developed for direct detection of the specific genes of bacteria in clinical and food samples, and many species- or genus-specific assays have been developed for such detection. Some of them are PCRbased assays (Hsu and Tsen, 2001) in which the discrimination of the target species is accomplished by the specific amplification of a unique region. Recently, a commercial real-time PCR-based assay that identifies 11 major pathogen species or groups responsible for IMI and a gene coding for staphylococcal $\beta$-lactamase production was validated for its analytical specificity and sensitivity (Koskinen et al. 2009). Other authors have integrated the PCR assay, performing a postamplification hybridization of the target sequence to a very small number of oligonucleotides on membrane (Lin and Tsen, 1999) or glass arrays (Sergeev et al., 2004). Generally, all these assays have targeted a limited number of species (i.e., most of them focused on only 1 and never on more than 6 species) and have required careful optimization for finding the appropriate conditions to amplify the specific target, with subsequent increases in detection time and overall assay duration. These hindrances have been partially circum- 

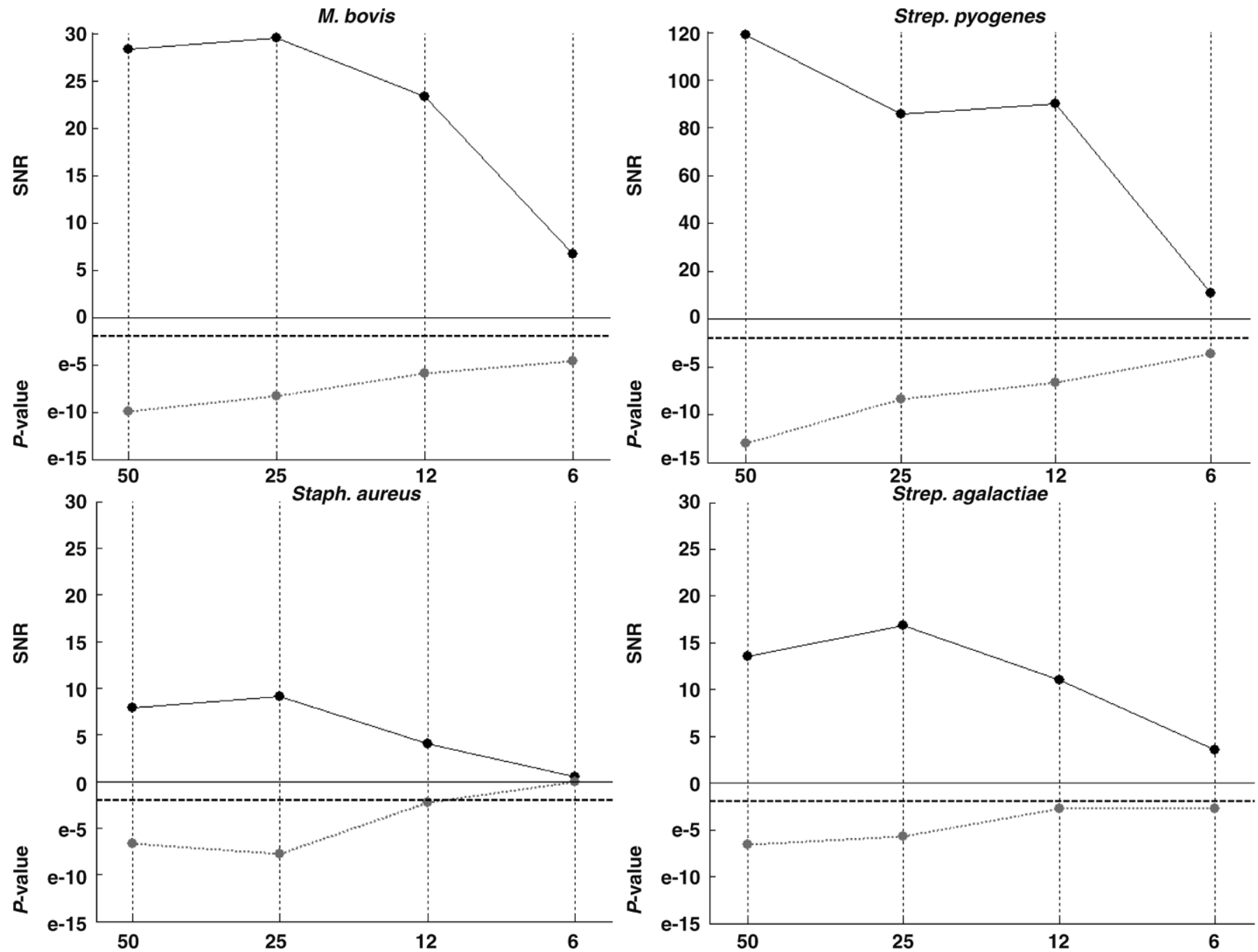

Figure 3. The signal-to-noise ratios (SNR; top, black line) and the unadjusted $P$-values (bottom, gray line, logarithmic scale) of the serial dilutions of Mycoplasma bovis (ATCC 25523), Streptococcus pyogenes (ATCC 12344), Staphylococcus aureus (ATCC 19095), and Streptococcus agalactiae (ATCC BAA611D). The $\mathrm{x}$-axis reports the quantity of PCR product (fmol). The threshold for significance $(P<0.01)$ is drawn as a dashed line.

vented in most recent works, which have targeted 11 or 13 pathogenic species at a time by analyzing the $16 \mathrm{~S}$ rRNA gene (Wang et al., 2007) or designing the probes by means of comparative genomics (Kim et al., 2008), respectively. However, these assays have not been able to discriminate Streptococcus at the species level and have required probes on different genes for detecting $E$. coli and Salmonella (Wang et al., 2007) or have shown some degree of aspecificity in detecting Staphylococcus spp., requiring at least $10 \mathrm{~h}$ to complete and $500 \mathrm{ng}$ of genomic DNA (Kim et al., 2008).

In this work, the molecular procedure chosen to discriminate among the different pathogen groups was the LDR-UA approach. The PCR-LDR-UA assay, including DNA extraction, PCR amplification, LDR, and data analysis, can be completed in less than $7 \mathrm{~h}$. This assay is based on the properties of DNA LDR and requires 2 specific probes for each target sequence, as first described by Gerry et al. (1999). The use of the LDR in addition to PCR greatly reduces the chances of false positives and results in high specificity, because the procedure is based on the discriminating power of the thermostable ligase that joins the ends of the 2 adjacent oligonucleotides designed for a given target [discriminating probe (DS) or common probe]. The $3^{\prime}$ end of the DS lies on the base that discriminates the target from among the others, whereas its $5^{\prime}$ end bears a fluorescent reporter. The common probe anneals immediately downstream of the discriminating position and has a phosphorylated $5^{\prime}$ end. Only when there is 


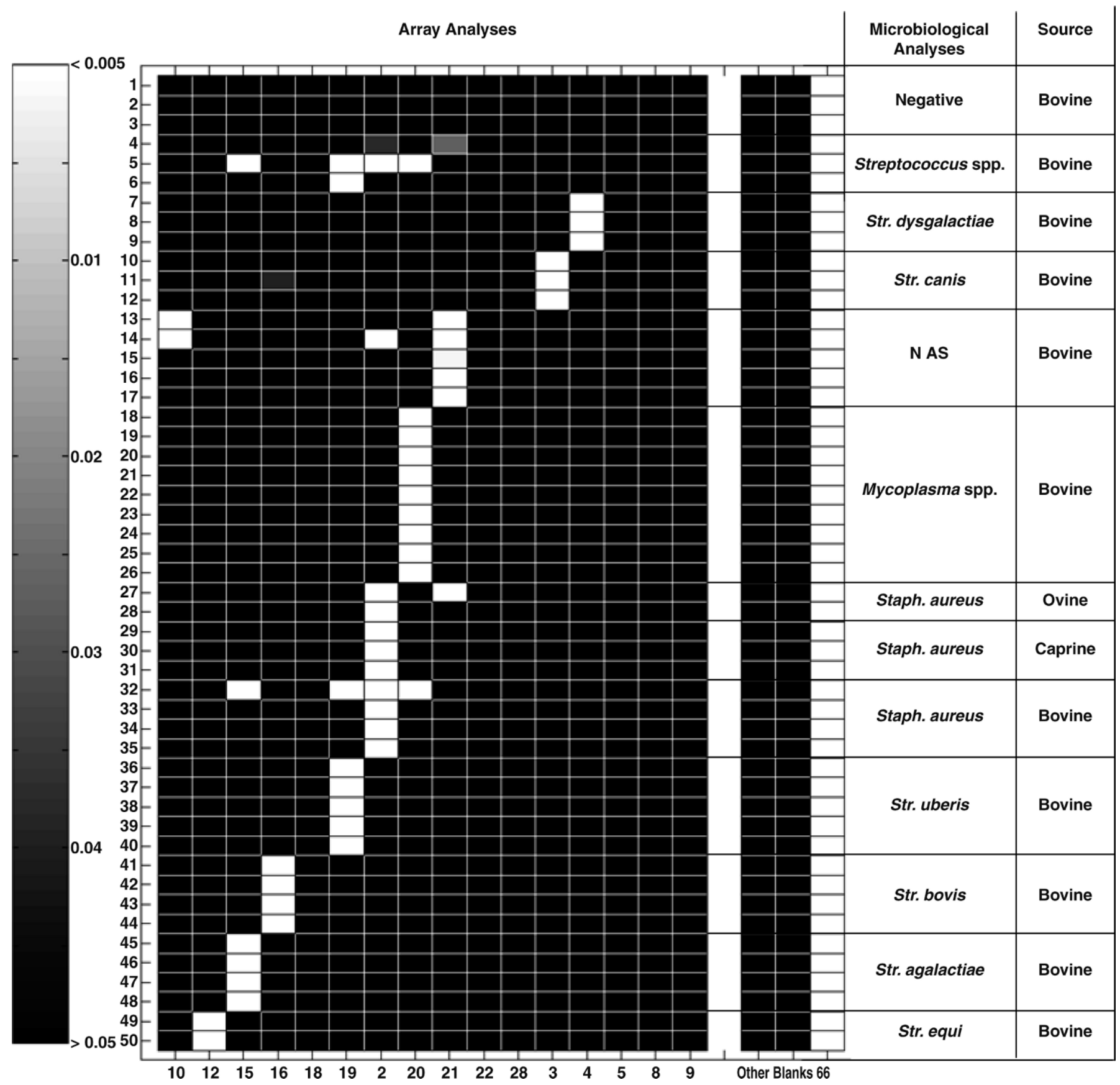

Figure 4. Heat map of unadjusted $P$-values for ligation detection reaction experiments on 50 milk samples. The map (on the left) indicates the $P$-value of the one-sided $t$-tests. No multiple comparisons correction has been made. The white color indicates a $P$-value of 0.005 or less, whereas the black color indicates a $P$-value of 0.05 or more. Threshold value of 0.01 is highlighted in light gray. Microbiological characterization and source of the samples are provided on the right. NAS = nonaureus staphylococci.

a perfect match between the 2 oligonucleotides does a thermostable ligase join the 2 ends and can the ligation process take place; an artificial sequence (called the ZipCode; Chen et al., 2000), added at the 3' end, then drives the ligated product to a specific position on the UA, where it can be detected. Use of terminal
3 '-specific DS to distinguish a species among the others maximizes the selectivity of the ligation process, and thus of the entire procedure. Another advantage of using LDR coupled with PCR in this context is the multiplexing capability of LDR. In the UA-based approach, the optimization of hybridization conditions 
for each probe set is not required because the melting temperatures of the ZipCodes are nearly the same (about $68^{\circ} \mathrm{C}$ ). New probe pairs can be added to the array without further optimization, thus reducing costs and setup time (Castiglioni et al., 2004; Chessa et al., 2007). In the current UA layout, up to 48 different species can be targeted independently, but there are no particular hindrances in increasing this number to 100. Moreover, this method can be used to analyze 8 different milk samples simultaneously, reducing the cost of analysis.

Proper design of probes is the key factor for successful oligonucleotide-based assays, relying either on hybridization or on enzymatic procedures. The $16 \mathrm{~S}$ rRNA is the most commonly used gene for designing oligonucleotide arrays because it has large conserved regions, useful for alignment and "universal" primer design and species-specific variations, capable of distinguishing genera and well-resolved species (Plays et al., 1997) while avoiding the use of several primer sets that might result into a poor amplification efficiency, and thus generating false-positive results (Wilson et al., 2002). The RDP II and BLAST were used in our study to achieve probes that showed optimal specificity and sensitivity for the target species.

In this work, we aimed for precise discrimination of similar species based on 16S rRNA pathogen-specific sequences. Our experimental data, analyzed by the typical $P$-value criterion on a $t$-distribution pattern $(<0.01)$ to determine hybridization differences, confirmed the high specificity of the LDR assay. In most experiments, the calculated $P$-value was well below 0.01 (Table 1 ), indicating that our detection platform was statistically effective for discriminating between target pathogens.

Significantly, the designed probes correctly differentiated the Streptococcus spp. causing mastitis: 1 probe was designed for the following species of the Streptococcus group (Strep. agalactiae, Strep. equi, Strep. dysgalactiae, Strep. uberis, Strep. parauberis, Strep. bovis, Strep. canis) to determine the prevalence of different species in dairy herds. The PCR-LDR-UA assay allowed for discrimination between Strep. uberis and Strep. parauberis on the basis of a single PCR on the $16 \mathrm{~S}$ rRNA gene, avoiding the use of species-specific PCR primers (Hassan et al., 2005). Probe pairs for Strep. equi and Strep. dysgalactiae were designed to identify any of the 2 subspecies of each. The discrimination of Strep. equi ssp. zooepidemicus from Str. equi ssp. equi and Str. dysgalactiae ssp. equisimilis from Str. dysgalactiae ssp. dysgalactiae is not possible with the present set of LDR probe pairs. A further refinement of the assay would be the design and testing of specific probe pairs for the zoonotically important subspecies. Moreover, the diagnosis of Mycoplasma spp., known to cause mastitis in cattle, sheep, and goats, is most commonly made by microbiological procedures, using different specific growth media and long incubation times (González and Wilson, 2003). Thus, isolation and identification of Mycoplasma spp. are notoriously difficult and timeconsuming. Strains of $M$. bovis, Mycoplasma agalactiae, Mycoplasma arginini, Mycoplasma capri, Mycoplasma capricolum, and Mycoplasma mycoides can be clearly identified as belonging to the Mycoplasma genus by the specific probe pair in the PCR-LDR-UA assay, providing an improved diagnostic method for this pathogen.

In our study, we showed that carefully designed specific oligonucleotide probes can distinguish Salmonella spp. from E. coli and related species (Table 1), which share large stretches of homologous regions within the amplified segments of the 16S rRNA gene. However, our probe pair, initially designed to be specific only for E. coli strains, was found in silico to recognize some Shigella strains as well, confirming that they cannot be distinguished on the basis of the $16 \mathrm{~S}$ rRNA gene, as stated by Wang et al. (2007).

From the probe sensitivity experiments, the PCRLDR-UA assay revealed a detection limit for Staph. aureus down to $12 \mathrm{fmol}$ of PCR product, well below the limit imposed by the European Union [Commission Regulation (EC) No. 2073/2005; http://eur-lex.europa. eu/JOIndex.do?ihmlang $=$ en; i.e., $500 \mathrm{cfu} / \mathrm{mL}$, corresponding to approximately $150 \mathrm{fmol}$. The sensitivity for 3 other species (M. bovis, Strep. pyogenes, Strep. agalactiae) was even better, resulting in $6 \mathrm{fmol}$.

Generally, the presence of typical endogenous microflora might mask the detection of foodborne pathogens. To determine the ability of the PCR-LDR-UA assay to identify pathogens in mixed bacterial populations, we prepared and analyzed artificially unbalanced DNA mixtures of different microbial species, obtaining efficient and highly specific detections (data not shown).

Finally, this method was evaluated using 50 bovine, ovine, and caprine milk samples; all the obtained bacterial identifications were in agreement with the result of the microbiological methods; moreover, the presence of other pathogens was assessed. For example, sample number 30, which was found to be positive for Staph. aureus by microbiological test, also revealed the presence of Mycoplasma spp., Strep. uberis, and Strep. agalactiae by PCR-LDR-UA.

In conclusion, we demonstrated the great potential of the DNA chip described herein for rapid, sensitive, and reliable identification, directly from milk samples, of the main pathogens known to cause mastitis in cattle, sheep, and goats or those responsible for foodborne intoxication or infection, or both. Further, the specific target spectra produced by this gene chip may be gradually expanded through addition of newly designed 
oligonucleotide probes into the microarray, without the optimization of hybridization conditions. In microbiological contexts, pathogen detection by means of DNA microarrays could be integrated into routine milk monitoring. The estimated unit cost is approximately $1 €$ per sample, including the oligonucleotide probes and all the reagents. The initially high costs for the eventual setup of a microarray laboratory (because of the spotting robot and the laser scanner) can be amortized over the medium term (approximately $3 \mathrm{yr}$ ). Moreover, many facilities offer the spotting and scanning service for reasonable costs. The LDR-UA assay, offering the power of a microarray format, will be expected to facilitate the analyses of several pathogens at the same time in the near future.

\section{ACKNOWLEDGMENTS}

This work was supported by a grant from Regione Lombardia (contract no. 962 "Safe Milk"). We are grateful to Giada Caredda (Institute of Biomedical Technologies-Italian National Research Council, Segrate, Italy) and Stefania Chessa (Department of Veterinary Science and Technology for Food Safety, University of Milan, Milan, Italy) for their technical assistance.

\section{REFERENCES}

Allos, B. M. 2001. Campylobacter jejuni infections: Update on emerging issues and trends. Clin. Infect. Dis. 32:1201-1206.

Altschul, S. F., T. L. Madden, A. A. Schäffer, J. Zhang, Z. Zhang, W. Miller, and D. J. Lipman. 1997. Gapped BLAST and PSI-BLAST: A new generation of protein database search programs. Nucleic Acids Res. 25:3389-3402.

Bergonier, D., X. Berthelot, M. Romeo, A. Contreras, V. Coni, E. De Santis, S. Roselu, F. Barillet, G. Lagriffoul, and J. Marco. 1999. Fréquence des différents germes responsables de mammites cliniques et subcliniques chez les petits ruminants laitiers. Pages 130-136 in Milking and Milk Production of Dairy Sheep and Goats. F. Barillet and P. Zervas, ed. Wageningen Pers, Wageningen, the Netherlands.

Blood, D. C., V. P. Studdert, and C. C. Gay. 2006. Saunders Comprehensive Veterinary Dictionary. 3rd ed. Saunders Ltd./ Elsevier Inc., Amsterdam, the Netherlands.

Bottero, M. T., A. Dalmasso, D. Soglia, S. Rosati, L. Decastelli, and T. Civera. 2004. Development of a multiplex PCR assay for the identification of the pathogenic genes of Escherichia coli in milk and milk products. Mol. Cell. Probes 18:283-288.

Brown, M. B., J. K. Shearer, and F. Elvinger. 1990. Mycoplasmal mastitis in a dairy herd. J. Am. Vet. Med. Assoc. 196:10971101.

Castiglioni, B., E. Rizzi, A. Frosini, K. Sivonen, P. Rajaniemi, A. Rantala, M. A. Mugnai, S. Ventura, A. Wilmotte, C. Boutte, S. Grubisic, P. Balthasart, C. Consolandi, R. Bordoni, A. Mezzelani, C. Battaglia, and G. De Bellis. 2004. Development of a universal microarray based on the ligation detection reaction and $16 \mathrm{~S}$ rRNA gene polymorphism to target diversity of cyanobacteria. Appl. Environ. Microbiol. 70:7161-7172.

Chen, J., M. A. Iannone, M.-S. Li, D. Taylor, P. Rivers, A. J. Nelsen, K. A. Slentz-Kesler, A. Roses, and M. P. Weiner. 2000 A microsphere-based assay for multiplexed single nucleotide polymorphism analysis using single base chain extension. Genet. Res. 10:549-557.
Chenna, R., H. Sugawara, T. Koike, R. Lopez, T. Gibson, D. G. Higgins, and J. D. Thompson. 2003. Multiple sequence alignment with the Clustal series programs. Nucleic Acids Res. 31:3497-3500.

Chessa, S., F. Chiatti, G. Cerotti, A. Caroli, C. Consolandi, G. Pagnacco, and B. Castiglioni. 2007. Development of a single nucleotide polymorphism genotyping microarray platform for the identification of bovine milk protein genetic polymorphisms. J. Dairy Sci. 90:451-464.

Consolandi, C., M. Severgnini, B. Castiglioni, R. Bordoni, A. Frosini, C. Battaglia, L. R. Bernardi, and G. De Bellis. 2006. A structured chitosan-based platform for biomolecule attachment to solid surfaces: Application to DNA microarray preparation. Bioconjug. Chem. 17:371-377.

Cremonesi, P., B. Castiglioni, G. Malferrari, I. Biunno, C. Vimercati, P. Moroni, S. Morandi, and M. Luzzana. 2006. Technical Note: Improved method for rapid DNA extraction of mastitis pathogens directly from milk. J. Dairy Sci. 89:163-169.

De Buyser, M.-L., B. Dufour, M. Maire, and V. Lafarge. 2001. Implication of milk and milk products in food-borne diseases in France and in different industrialized countries. Int. J. Food Microbiol. 67:1-17.

Devriese, L. A., J. Hommez, H. Laevens, B. Pot, P. Vandamme, and F. Haesebrouck. 1999. Identification of aesculin-hydrolyzing streptococci, lactococci, aerococci and enterococci from subclinical intramammary infections in dairy cows. Vet. Microbiol. 70:8794.

Edwards, U., T. Rogall, H. Blocker, M. Emde, and E. C. Bottger. 1989. Isolation and direct complete nucleotide determination of entire genes. Characterization of a gene coding for $16 \mathrm{~S}$ ribosomal RNA. Nucleic Acids Res. 17:7843-7853.

Fox, L. K., J. H. Kirk, and A. Britten. 2005. Mycoplasma mastitis: A review of transmission and control. J. Vet. Med. B, Infect. Dis. Vet. Public Health 52:153-160.

Gerry, N. P., N. E. Witowski, J. Day, R. P. Hammer, G. Barany, and F. Barany. 1999. Universal DNA microarray method for multiplex detection of low abundance point mutations. J. Mol. Biol. 292:251-262.

González, R. N., and D. J. Wilson. 2003. Mycoplasmal mastitis in dairy herds. Vet. Clin. North Am. Food Anim. Pract. 19:199-221.

Granum, P. E. 2001. Bacillus cereus. Pages 373-381 in Food Microbiology: Fundamentals and Frontiers. 2nd ed. M. P. Doyle, L. R. Beuchat, and T. J. Montville, ed. ASM Press, Washington, DC.

Hassan, A. A., O. Akineden, and E. Usleber. 2005. Identification of Streptococcus canis isolated from milk of dairy cows with subclinical mastitis. J. Clin. Microbiol. 43:1234-1238.

Honkanen-Buzalski, T., V. Myllys, and S. Pyörälä. 1994. Bovine clinical mastitis due to coagulase-negative staphylococci and their susceptibility to antimicrobials. J. Vet. Med. B 41:344-350.

Hsu, S. C., and H. Y. Tsen. 2001. PCR primers designed from malic acid dehydrogenase gene and their use for detection of Escherichia coli in water and milk samples. Int. J. Food Microbiol. 64:1-11.

Jayarao, B. M., S. C. Donaldson, B. A. Straley, A. A. Sawant, N. V. Hegde, and J. L. Brown. 2006. A survey of foodborne pathogens in bulk tank milk and raw milk consumption among farm families in Pennsylvania. J. Dairy Sci. 89:2451-2458.

Jayarao, B. M., B. E. Gillespie, M. J. Lewis, H. H. Dowlen, and S. P. Oliver. 1999. Epidemiology of Streptococcus uberis intramammary infections in a dairy herd. J. Vet. Med. B 46:433-442.

Kim, H.-J., S.-H. Park, T.-H. Lee, B.-H. Nahm, Y.-R. Kim, and H.-Y. Kim. 2008. Microarray detection of food-borne pathogens using specific probes prepared by comparative genomics. Biosens. Bioelectron. 24:238-246.

Koskinen, M. T., J. Holopainen, S. Pyörälä, P. Bredbacka, A. Pitkälä, H. W. Barkema, R. Bexiga, J. Roberson, L. Sølverød, R. Piccinini, D. Kelton, H. Lehmusto, S. Niskala, and L. Salmikivi. 2009. Analytical specificity and sensitivity of a real-time polymerase chain reaction assay for identification of bovine mastitis pathogens. J. Dairy Sci. 92:952-959.

Lin, C. K., and H. Y. Tsen. 1999. Comparison of the partial 16S rRNA gene sequences and development of oligonucleotide probes 
for the detection of Escherichia coli cells in water and milk. Food Microbiol. 16:551-562.

Little, C. L., J. R. Rhoades, S. K. Sagoo, J. Harris, M. Greenwood, V. Mithani, K. Grant, and J. McLauchlin. 2008. Microbiological quality of retail cheeses made from raw, thermized or pasteurized milk in the UK. Food Microbiol. 25:304-312.

Ludwig, W., O. Strunk, R. Westram, L. Richter, H. Meier, Yadhukumar, A. Buchner, T. Lai, S. Steppi, G. Jobb, W. Förster, I. Brettske, S. Gerber, A. W. Ginhart, O. Gross, S. Grumann, S. Hermann, R. Jost, A. König, T. Liss, R. Lüßmann, M. May, B. Nonhoff, B. Reichel, R. Strehlow, A. Stamatakis, N. Stuckmann, A. Vilbig, M. Lenke, T. Ludwig, A. Bode, and K. H. Schleifer. 2004. ARB: A software environment for sequence data. Nucleic Acids Res. 32:1363-1371.

National Mastitis Council. 1999. Laboratory Handbook on Bovine Mastitis. Rev. ed. National Mastitis Council Inc., Madison, WI.

Oviedo-Boyso, J., J. J. Valdez-Alarcón, M. Cajero-Juárez, A. OchoaZarzosa, J. E. López-Meza, A. Bravo-Patiño, and V. M. BaizabalAguirre. 2007. Innate immune response of bovine mammary gland to pathogenic bacteria responsible for mastitis. J. Infect. 54:399 409.

Pengov, A. 2006. Staphylococcus aureus-Do we really have to live with it? Slov. Vet. Res. 43:41-46.

Pingle, M. R., K. Granger, P. Feinberg, R. Shatsky, B. Sterling, M. Rundell, E. Spitzer, D. Larone, L. Golightly, and F. Barany. 2007. Multiplexed identification of blood-borne bacterial pathogens by use of a novel 16S rRNA gene PCR-ligase detection reactioncapillary electrophoresis assay. J. Clin. Microbiol. 45:1927-1935.

Pisoni, G., R. N. Zadoks, C. Vimercati, C. Locatelli, M. Zanoni, and P. Moroni. 2009. Epidemiological investigation of Streptococcus equi subspecies zooepidemicus involved in clinical mastitis in dairy goats. J. Dairy Sci. 92:943-951.

Pitkala, A., M. Haveri, S. Pyorala, V. Myllys, and T. HonkanenBuzalski. 2004. Bovine mastitis in Finland 2001-Prevalence, distribution of bacteria, and antimicrobial resistance. J. Dairy Sci. $87: 2433-2441$.

Palys, T., L. K. Nakamura, and F. M. Cohan. 1997. Discovery and classification of ecological diversity in the bacterial world: The role of DNA sequence data. Int. J. Syst. Bacteriol. 47:1145-1156.

Sergeev, N., M. Distler, S. Courtney, S. F. Al-Khaldi, D. Volokhov, V. Chizhikov, and A. Rasooly. 2004. Multipathogen oligonucleotide microarray for environmental and biodefense applications. Biosens. Bioelectron. 20:684-698.

Wang, X.-W., L. Zhang, L. Q. Jin, M. Jin, Z. Q. Shen, S. An, F. H. Chao, and J.-W. Li. 2007. Development and application of an oligonucleotide microarray for the detection of food-borne bacterial pathogens. Appl. Microbiol. Biotechnol. 76:225-233.

Watts, J. L. S. C. Nickerson, and J. W. Pankey. 1984. A case study of Streptococcus group G infection in a dairy herd. Vet. Microbiol. 9:571-597.

Wilson, W. J., C. L. Strout, T. Z. DeSantis, L. J. Stilwell, A. V. Carrano, and G. L. Andersen. 2002. Sequence-specific identification of 18 pathogenic microorganisms using microarray technology. Mol. Cell. Probes 16:119-127.

Wong, H. C., Y. L. Chen, and C. L. F. Chen. 1988. Growth, germination and toxigenic activity of Bacillus cereus in milk products. J. Food Prot. 51:707-710. 